\title{
SENSITIVITY AND MAGNETIC SHIELDING TESTS OF A THOMSON GALVANOMETER FOR USE IN RA- DIOMETRY
}

By W. W. Coblentz

CONTENTS

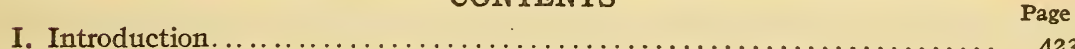

II. Experimental tests of galvanometer coils.................... 424

I. The form of the coil ........................... 424

2. The standard coils ........................... 426

3. Method of comparison of various coils ................ 428

4. Discussion of the results of tests on various coils........... 428

III. Comparison of astatic magnet systems. ..................... 43 I

IV. Test of shielding against magnetic disturbances ............... 432

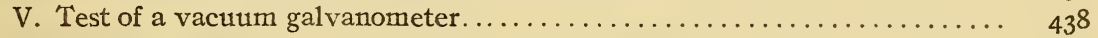

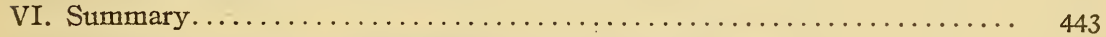

Appendix.-Note I. Mounting for vacuum thermopiles ............ 444

\section{INTRODUCTION}

In attempting a further improvement in stellar radiometry ${ }^{1}$ it was deemed desirable to inquire first into the construction of the galvanometer which is one of the three important elements in the radiometric apparatus, the other two elements being the thermocouple and the reflecting mirror. As indicated in the previous paper, a further improvement in the stellar thermocouple will depend more upon the nicety of construction than upon the emf of the thermoelement. New alloys having a high thermal emf and a high tensile strength must, of course, be sought. However, if the thickness of the material can not be reduced to smaller dimensions than those already employed, then the prospects for greatly increasing the sensitivity of the thermocouple are not very encouraging.

A further increase in the galvonometer sensitivity must evidently be sought through further improvements in the coils and especially in the suspended magnet system. In spite of all that has been written upon the construction of galvanometer coils, wound in sections of graded wire, there seemed to be no data at hand showing the behavior of the different sections as compared 
with what was to be expected from theory. In fact, part of the present investigation is the result of a disagreement between the observed and the theoretical performmance of the different sections of several galvanometer coils which had beein subjected to test. This paper gives the results of experiments (I) on galvanometer coils of various designs, (2) on various magnet systems, (3) on shielding the galvanometer from magnetic disturbances, and (4) on vacuum galvanometers.

The increase in sensitivity as a result of placing the magnet system in an evacuated inclosure has already been discussed, ${ }^{2}$ and more precise data are given in the present paper. In the previous tests the instrument could not be shielded from magnetic disturbances. In the vacuum galvanometer, as it will be used in practice, one of the inner shields is to be provided with a cover, so that it can be utilized as an inclosure which may be evacuated. The sensitivity attainable will depend upon the weight and upon the period that can be given to the suspended magnet system. This will, of course, depend upon the environment in which the instrument $\pi$ ill be used. From the performance of the instrument when shielded, as described on a subsequent page, it appears that magnetic disturbances can be reduced to a very small value. It is to be emphasized, however, that with such a highly shielded galvanometer it is difficult to maintain a long period because of the necessity of using powerful control magnets which must be placed close to the galvanometer. These control magnets are so close that any slight change in their position, or in the magnetic force exerted by them, easily affects the astaticism of the needle.

\section{EXPERIMENTAL TESTS OF GALVATOMETER COILS}

\section{TEE FORM OF THE COII}

This subject has received so much discussion that there seems to be little need for further remarks. Maxwell has shomn that each layer of spires should lie within the surface having the polar equation $r^{2}=d^{2} \sin \theta$, where $r$ is the length of the radius (the distance from the magnet of infinitesimal length) making an angle $\theta$ with the axis of the coil, and $d$ the value of $r$ when $\theta=90^{\circ}$. Freudenberger ${ }^{3}$ has used the formula $r=p \sin ^{2} \theta$, which produces a thinner coil than obtained by using the original formula. He was interested in a coil having a resistance of about roo ohms and found that a coil made of No. 36 B. \& S. wire was as good as one 
made of wires of different diameters. In fact, he mentions that coils might be wound to the resistance desired, using No. 36 wire.

It has been shown ${ }^{4}$ that if the space in which the needle hangs is not made cylindrical, the shape of it is of some importance, as it is possible to place spires in positions in which they produce a magnetic effect which is opposed to that of the complete coil.

Abbot ${ }^{5}$ has made theoretical computations of the force exerted by coils wound in three sections, of equal resistance of graded wire. The data published give the force exerted by each section of the coil.

No experimental tests having been published, the writer made tests of the force exerted by each of the three sections of a $20-0 h m$ coil (the 2I.I-ohm coil in Table I), which had been wound according to theoretical specifications to give the maximum total force.

The theoretical data indicated that the force exerted should be closely the same for each section of this particular type of coil. However, as a general rule, this is not necessary in order to obtain a coil that exerts the maximum total force. The results of this test (see Table I) showed that experimentally (cwing to difficulties in winding the coils) the force exerted by each section of the 20-ohm coil is not the same as was to be expected from theoretical considerations, and that the outer section exerted the greatest force. In other words, the outer section is the most efficient of the three components of this $20-0 h m$ coil. The inner section was found to be the least efficient, and in view of the fact that a galvanometer was desired which had a lower resistance than was obtainable with these 20-ohm coils joined in parallel, it was deemed desirable to determine whether (without making a prolonged investigation) an efficient coil could be found bytrial, which had the properties of the central and outer sections of the 20-ohm coil. As is well known and as was mentioned in a previous paper, ${ }^{6}$ owing to the difficulties in winding fine wires and owing to the large amount of space occupied by the insulation when using fine wires, a more sensitive 4-ohm coil galvanometer is to be expected to result from constructing the coils of heavy wires (hence of low resistance, say $2.5 \mathrm{ohms}$ ) which are joined in series than is to be expected to result from coils of the same size which are wound with fine wire (hence of high resistance, say Io

4 Ayrton, Mather, and Sumpner, Phil. Mag., 30, p. 58; I890.

5 Abbot, Astrophys. Jour., 18, p. I, I903; Ann. Astrophys. Obs., 1, p. 250 , 1902.

6 This Bulletin, 11, pp. I80-I8i. (See Fig. 9.) 
ohms) which are joined in series parallel. However, as will be shown presently, these two kinds of coils differed but little in the force exerted, although the wires had been selected to give closely the same sized coils. In previous tests no marked difference was found in galvanometers having $20-0 \mathrm{hm}$ coils wound in three and in five sections of graded wire. The records of the performance of 12 galvanometers indicate (as mentioned in the paper just quoted) that the greatest advances in increasing the sensitivity
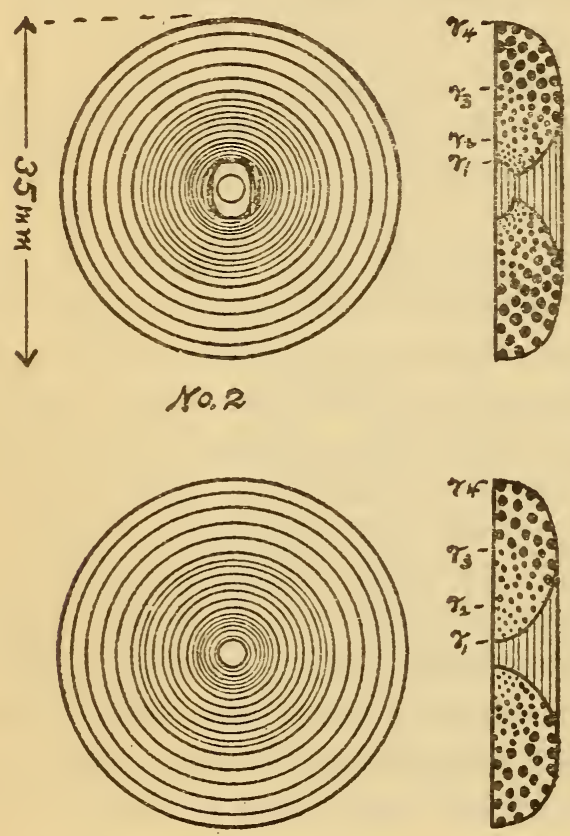

No. 1

FIG. I.-Form of the coil when using different mandrels of the galvanometer are to be expected from improvements in the suspended system.

The mandrels used in winding the coils were of two types, producing coils of the form shown in Fig. I, which shows a compound coil wound in three sections of graded wire. Mandrel No. 2 was tried to determine whether a marked

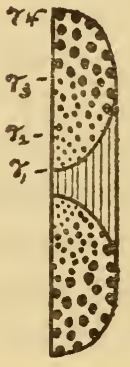
improvement would result in the magnetic field near the galvanometer needles. When using fine wires for the inner section of the coil, this form of winding (mandrel No. 2) was found to be detrimental.

In the coils to be described presently the insulation was a single layer of silk, excepting in the o.6-ohm coil, which was covered with a double layer of

silk. The thickness of the insulation was about $0.043 \mathrm{~mm}$, which is practically the same as used by Abbot (loc. cit.). The thickness of the various samples of wire, some of which had been purchased (from A. F. Moore, Philadelphia) eight years ago, varied from 0.001 to $0.002 \mathrm{~mm}$.

\section{THE STANDARD COILS}

All the coils investigated were compared with a set of three coils, which was used as a standard. These three coils were mounted securely in an ironclad support, two in the lower part 
Bullotin Bureau of Standards, Vol. 13

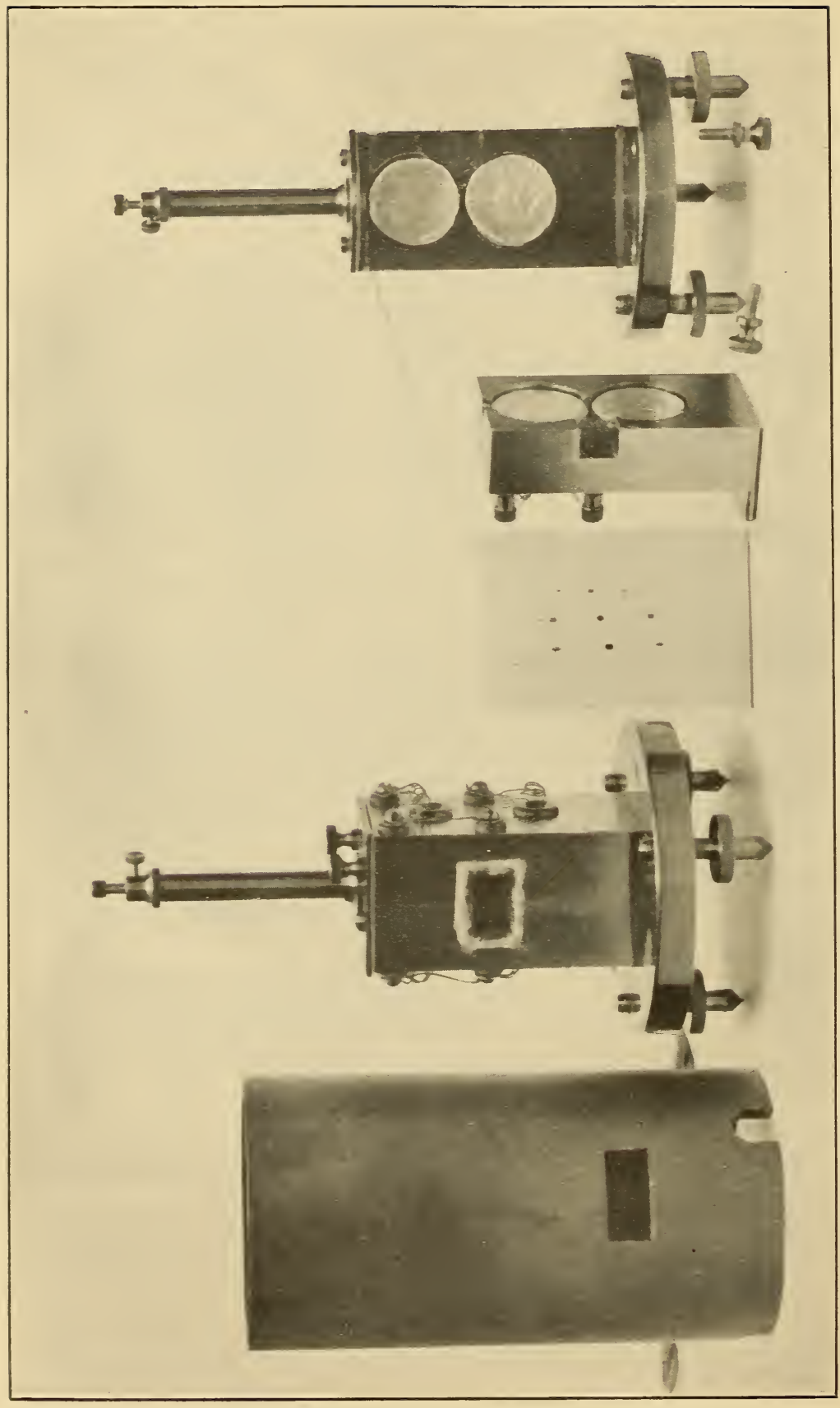

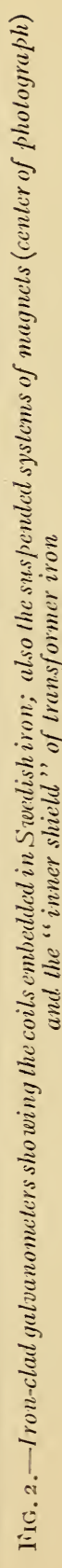


and one in the upper position, as shown in Fig. 2. The coil which was to be compared was mounted at a fixed distance opposite the upper standard coil. The object of the three standard coils was to enable one to test the symmetry of the deflections of the suspended magnet system, which might be affected in mounting the various coils which were being tested. Lead wires from each coil, or sections of a coil, were connected with small mercury cups in a block of paraffin. By this means it was possible to send an electric current through any coil in the instrument. After mounting a coil for comparison the iron shields were put in place and the magnet system was astatized to give a single swing of two to three seconds. The symmetry of the deflections produced by the three standard coils was not affected by slight changes in level. It was therefore assumed that the coils under examination were being intercompared with considerable accuracy.

The details of construction of the standard coils are given in Table I. Each coil was wound in two sections and had a resistance of 10.2 ohms. The form of the coil is shown in No. 2 of Fig. I. As shown in Table I, another ro-ohm coil wound, with three kinds of wire, on mandrel No. I, Fig. $\mathrm{I}$, is $\mathrm{I} 7$ per cent more efficient than the one which happened to be used as a standard.

\section{TABLE 1}

Efficiency of Coils of Various Design as Compared with a Set of Standard Coils

\begin{tabular}{|c|c|c|c|c|c|c|c|c|c|}
\hline \multicolumn{6}{|c|}{ Specifications of coils } & \multicolumn{2}{|c|}{ Force exerted } & \multicolumn{2}{|c|}{$\begin{array}{c}\text { Efficiency } \\
\text { as compared } \\
\text { with standard }\end{array}$} \\
\hline \multirow{2}{*}{$\begin{array}{l}\text { Re- } \\
\text { sist- } \\
\text { ance }\end{array}$} & $\begin{array}{l}\text { Kind of } \\
\text { wire }\end{array}$ & Radii of sections & \multicolumn{2}{|c|}{$\begin{array}{l}\text { Resistance } \\
\text { of sections }\end{array}$} & \multirow{2}{*}{$\begin{array}{l}\text { Man- } \\
\text { drel }\end{array}$} & By each section & \multirow{2}{*}{$\begin{array}{c}\begin{array}{c}\text { Ratio; } \\
\text { standard }\end{array} \\
\text { test }\end{array}$} & \multirow{2}{*}{$\begin{array}{c}\text { Test } \\
\text { coils in } \\
\text { series }\end{array}$} & \multirow{2}{*}{$\begin{array}{l}\text { Test } \\
\text { coils in } \\
\text { series } \\
\text { par- } \\
\text { allel }\end{array}$} \\
\hline & $\begin{array}{lll}\mathbf{r}_{1} & \mathbf{r}_{2} & \mathbf{r}_{3}\end{array}$ & $\begin{array}{llll}\mathbf{r}_{1} & \mathbf{r}_{2} & \mathbf{r}_{3} & \mathbf{r}_{4}\end{array}$ & 1 & 3 & & 23 & & & \\
\hline ohms & & $\mathbf{m m}$ & ohn & & & & & & \\
\hline 0.62 & $\mathrm{No}_{5} 22$ & 17.0 & & 0.62 & 2 & & 4. $0: 1$ & 1.00 & \\
\hline 2. 26 & 2824 & $\begin{array}{lll}5.0 & 9.5 & 16.5\end{array}$ & 1.20 & 1.06 & 2 & 1.01 .11 & 1. $79: 1$ & 1.18 & 1. 18 \\
\hline 2.43 & 2824 & 1.59 .017 .0 & 1.30 & 1.13 & 1 & 1.00 .83 & 1. $73: 1$ & 1.18 & 1. 18 \\
\hline 3.17 & 2826 & $5.0 \quad 8.516 .5$ & 1.07 & 2. 10 & 2 & 1.01 .3 & $1.95: 1$ & & .92 \\
\hline 6.3 & 28 & $2.5 \quad 15.5$ & & 6.3 & 1 & & 1. $10: 1$ & & \\
\hline 8.6 & 3228 & 2.57 .016 .0 & 2.2 & 6.4 & 1 & 1.01 .88 & $0.946: 1$ & & 1. 17 \\
\hline 10.2 & 3428 & $4.0 \quad 6.0 \quad 15.5$ & 3.16 & 7.04 & 2 & 1.03 .66 & $\begin{array}{l}\text { Stand- } \\
\text { ard coil }\end{array}$ & & \\
\hline 10.5 & 343028 & $\begin{array}{llll}2.0 & 4.3 & 8.5 & 14.2\end{array}$ & 3.13 & 3. 63.8 & 1 & 1.01 .11 .05 & $0.856: 1$ & & 1.17 \\
\hline 11.1 & 3028 & 5.010 .017 .0 & 4.2 & 6.9 & 2 & 1.01 .26 & $0.922: 1$ & & \\
\hline 20.8 & 403632 & $\begin{array}{llll}1.2 & 3.2 & 5.0 & 9.5\end{array}$ & & & 1 & & $0.78: 1$ & & \\
\hline 21.0 & $3834 \quad 28$ & & & & 1 & $1.01 .18 \quad 1.26$ & & & \\
\hline 21.1 & $3834 \quad 28$ & $\begin{array}{llll}1.5 & 4.5 & 7.5 & 16.5\end{array}$ & 6.77 & 7.06 .8 & 1 & 1.01 .401 .83 & $0.622: 1$ & & \\
\hline
\end{tabular}




\section{METHOD OF COMPARISON OF VARIOUS COILS}

The behavior of the coil under test was determined by observing the deflection produced by a given current as compared with the defiection produced by the same current when passed through the standard coils. From tests made at various times throughout this investigation it was found that each one of the three standard coils produced the same deflections. The upper standard coil was therefore used in making the comparison. In Table I column 6 is given the force exerted by different sections of a coil, the inner section, "No. I," of each coil being used as a standard of reference. Column 7 gives the force exerted by the upper standard coil as compared with the coil under test. This of course is merely an intermediate step, for the comparison must be made with galvanometer coils having the same resistance. Columns 8 and 9 give the desired data, which will be discussed on a subsequent page. It will be sufficient to add that by efficiency is meant the ratio of the force exerted by the test coil as compared with the standard coil (of I0.2 ohms) when used under comparable conditions. For example, the $0.62-0 h m$ coils would be joined all in series, giving a galvanometer resistance of $2.48 \mathrm{ohms}$, while the standard $10.2-0 \mathrm{hm}$ coils would be joined all in parallel, giving a resistance of $2.55 \mathrm{ohms}$.

In the thermopiles described in previous papers the elements were joined either all in series, producing a resistance of about 9 ohms, or joined two in series parallel, producing a resistance of about 2 ohms. Table I therefore gives the way in which the above coils would be used in connection with these thermopiles. The efficiency of each coil is of course the same in whatever manner it may be connected. In reducing this data, the force exerted by the coil is assumed to be proportional to the square root of its resistance. This, however, is of minor.importance in view of the fact that comparison is made only of coils having closely the same resistance.

\section{DISCUSSION OF THE RESULTS OF TESTS ON VARIOUS COILS}

The results obtained on the different coils are summarized in Table I. As already mentioned, the Io-ohm coils used as standards of comparison happened to be less efficient than some of the coils under investigation. From Table I it may be noticed that a I0.5-Ohm coil made of three sizes of wire (American gauge Nos. 34,30 , and 28 ), an $8.6-0 \mathrm{hm}$ coil made of two sizes of wire (Nos. 32 and 28), and a 2.4-ohm coil made of two sizes of wire (Nos. 28 
and 24), all of which were practically the same in size, exert the same force, which is about 18 per cent greater than the standard. In the test on the 2.26 -ohm coil both types of mandrels (Fig. I) were used in order to determine whether in using Nos. 28 and 24 wire, a greater efficiency would result from placing the wires nearer the center of the coil. (See test of a 2.43-ohm coil, mandrel No. I.) As shown in Table I (force exerted), these two coils differ by only 3 per cent (I.79:I.73) in the force they exerted. It is of interest to note that in the $2.26-\mathrm{ohm}$ coil the outer section exerts a force which is I I per cent greater than that exerted by the inner section, while in the 2.43-ohm coil the inner coil exerts the greater force. The latter coil is the more efficient, showing that although the spires are nearer the magnets they do not occupy positions in which they produce a magnetic effect which is opposed to that of the complete coil. ${ }^{7}$ The efficiency of these types of coils (2.4, 8.6, and I0.5 ohms, respectively) being so closely the same there is no choice in their use with an external resistance of 2 or 8 ohms. As mentioned elsewhere, ${ }^{8}$ a galvanometer, in which the coils have a resistance of 8 ohms, is the most suitable to be used with bismuth-silver (or copper) thermopiles which have a resistance of about 8 ohms, when all the elements are joined in series, and a resistance of 2 ohms when the elements are connected in series parallel. Comparing the 8.6-ohm coils joined in series parallel with the $2.26-\mathrm{ohm}$ coils connected all in series, it was found that the latter arrangement was about 2 per cent more efficient than the $8.6-\mathrm{ohm}$ coils.

The performance of the $6.3-\mathrm{ohm}$ coil is of interest in view of the fact that it was made of a single size (No. 28) wire, to utilize the best part of the 2I.I-ohm coil previously mentioned. It produced a deflection of $2.67 \mathrm{~cm}$; and under the same conditions the 2I.I-ohm coil, of graded wire, gave a deflection of $5.07 \mathrm{~cm}$. When used with an external resistance of about 6 ohms, the above 6.3ohm coils would be joined in series parallel, thus producing a deflection of $5.34 \mathrm{~cm}$. Similarly, the four $2 \mathrm{I} . \mathrm{I}-\mathrm{ohm}$ coils would all be joined in parallel, having a resistance of $5.3 \mathrm{ohms}$ and producing a deflection of $5.07 \mathrm{~cm}$; or $5.53 \mathrm{~cm}$ on the basis of equal resistance. There is therefore but little difference (only 4 per cent) in the efficiency of these two coils. Of course, a 6-ohm coil of graded wire may perhaps be found which exerts a greater force than this coil which was made of a single size of wire. However, 
the gain in the force exerted by the 6-ohm coil of graded wire can not be expected to be very great in view of the fact that, theoretically, a 4-coil galvanometer of 6-ohm coils joined in series parallel is no more efficient than a galvanometer of $24-0 \mathrm{hm}$ coils joined all in parallel, and in view of the fact that in practice the low-resistance coils joined in series were found to be but little more efficient than coils of four times this resistance, which were joined all in parallel. Other facts must also be considered; for example, the range of proportionality of deflection with current may be small for the 6-ohm coil of single wire, while it is known to hold over a wide range ( $20 \mathrm{~cm}$ deflection, scale at I $\mathrm{m}$ ) in the 21 .I-ohm coil.

The data on the $2 \mathrm{I}-\mathrm{ohm}$ coils are of interest in view of the fact that this type of coil has been extensively used, being wound to fit closely the theoretical specifications. The coil is in three sections of Nos. 38,34 , and 28 wire. One peculiarity in this type of coil is that the force exerted by the inner section is from 50 to 60 per cent less than that exerted by the outer section, although the force exerted was supposed to be closely the same for each section. Another coil of this type gave similar results. That this is not due to the fact that the coils were imbedded in Swedish iron was proven by repeating the test on coils mounted in a brass support. The explanation is no doubt to be found in the fact that when using the finest wire with its disproportionately thick insulation as compared with a heavy wire, the resistance per turn of wire increases much more rapidly than obtains in the heavier wire. The outer section contains more than I5 times the length of wire, for the same resistance, and, as is well known, after passing out a certain distance from the center of the coil, the force exerted by each turn decreases but little with increase in diameter. All the coils just described are from $3 \mathrm{I}$ to $34 \mathrm{~mm}$ in diameter.

The 20.8-ohm coil (Table I) is one of the earliest designs worked with by the writer. ${ }^{9}$ This coil has a rather small diameter and its performance is poor. The proportionality of deflection to current does not obtain for deflections greater than 6 to $7 \mathrm{~cm}$. This coil gave a deflection of $4.05 \mathrm{~cm}$ under the same conditions as obtained in the test of the 2I.I-ohm coil (33 mm diameter) which gave a deflection of $5.15 \mathrm{~cm}$. In other words, the 2I.I-ohm coil was 27 per cent more efficient than the smaller sized coil having the same resistance. This had already been found from tests on a complete galvanometer containing the small coils and

This Bulletin, 4, p. 392, I908; Mendenhall and Waidner, Amer. Jour. Sci. (4), 12, p. 249 , Igsr. 
a more suitable magnet system as compared with the 2I.I-ohm coils (Fig. 2, the opened galvanometer to the right in this photograph) which were used with the vacuum thermocouples used in measuring the radiation from stars. The foregoing data are necessarily of a preliminary nature in view of the numerous factors which enter into the design of efficient galvanometer coils. The chief aim in the present communication is to call attention to the disagreement between certain theoretical specifications and the results obtained by experiment, which emphasizes the importance of further investigations.

\section{COMPARISON OF ASTATIC MAGNET SYSTEMS}

Various experimenters have made tests on the lengths of the magnets to be used in a galvanometer suspension, and the conclusion arrived at is that the magnets should be from I.5 to 2 $\mathrm{mm}$ in length. The tests from which these conclusions were drawn were made on single magnets. In view of the fact that the size of the mirror is a very important factor in determining the sensitivity, it was deemed of importance to make tests on complate magnet systems in which the mirrors were of the same size and thickness ${ }^{10}$ and only the lengths of the magnets were varied. Each system consisted of two groups of magnets (tungsten steel "glass hard" magnetized in a $\Sigma コ$ shaped device after mounting), four magnets in each group, the width of each magnet being about $0.25 \mathrm{~mm}$ and the thickness being about $0.1 \mathrm{~mm}$.

In one system (Fig. 3, $\Delta \Delta \Delta$ ), the magnets were $2 \mathrm{~mm}$ long; in the other system the magnets were $4 \mathrm{~mm}$ long. (Fig. 3, $x \times x$ ), and the latter gave only about two-thirds the deflection of the former for the same stimulus. In this test the mirrors were 2.0 by $2.8 \mathrm{~mm}$. In another suspension having needles 2.2 $\mathrm{mm}$ long and having mirror $3 \mathrm{~mm}$ diameter the sensitivity (Fig. $3, \odot \odot \odot)$ is the same as for the long needles. In other words, the large mirror reduces the sensitivity by about 30 per cent.

In another suspended system of magnets a decrease in sensitivity of over 20 per cent was introduced by substituting a mirror $2.5 \mathrm{~mm}$ in diameter for one which was 1.5 by $2.5 \mathrm{~mm}$. In the latter the longer edge was, of course, placed vertically in order to reduce the inertia.

In Fig. 2 are shown several astatic magnet systems. The largest one contains eight magnets (in two groups) each one of which is $2 \mathrm{~mm}$ in length. The mirror is rotated $90^{\circ}$ from its true posi-

10 This Bulletin, 11, p. I77; 1914. "Galvanometer Mirrors." 
tion to show its size. The distance between the two sets of magnets is $35 \mathrm{~mm}$. The next to the largest magnet system belongs to the galvanometer to the right in the photograph. It was used in measuring the heat from stars. The smallest magnetic system (magnets I mm long) was used with the 20.8-ohm coils (just described), which were $20 \mathrm{~mm}$ in diameter.

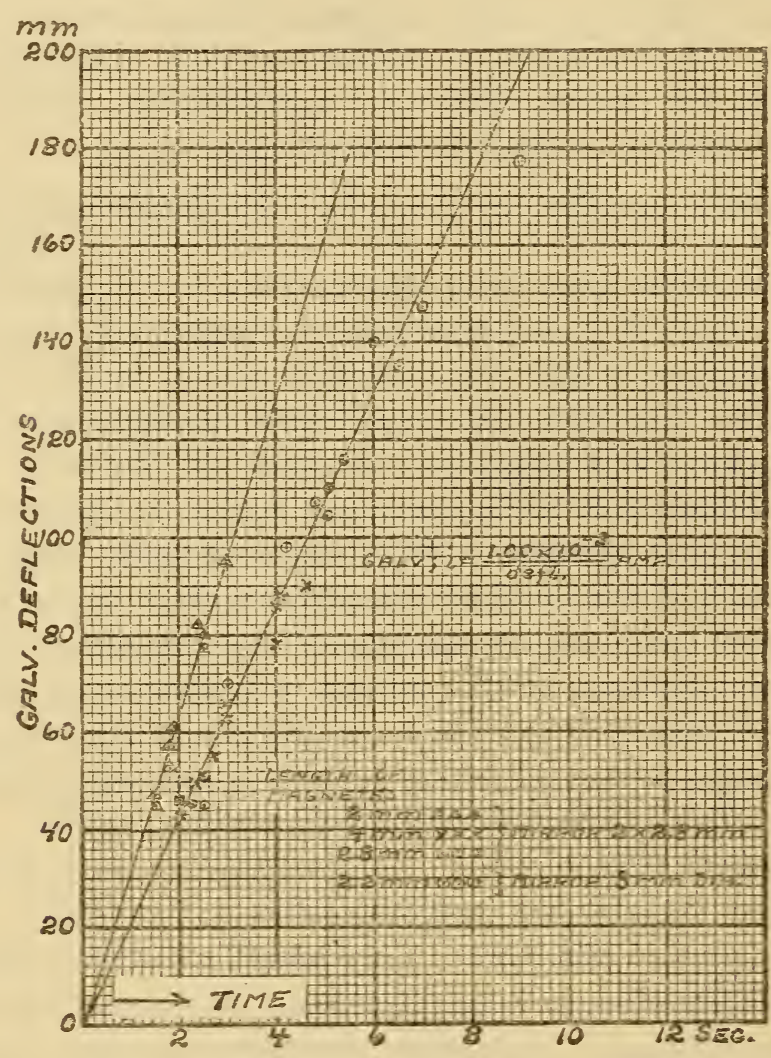

FIG. 3.-Variation of sensitivity with length of needle

\section{TEST OF SHIELDING AGAINST MAGNETIC DISTURBANCES}

The greatest advances in the improvement of the Thomson galvanometer in recent years hare resulted from providing it with a suitable protection against magnetic perturbations and air currents. The latter can, of course, be eliminated by placing the instrument in an evacuated inclosure (which procedure increases the sensitivity) but new difficulties are then encountered. In the present design, in which the coils are embedded in blocks of Swedish iron, there is but little air space, and the unsteadiness of the 
galvanometer needle by air currents is eliminated. In such an instrument a current sensitivity of $i=2 \times 10^{-10}$ amperes (scale at $2 \mathrm{~m}$ ) is easily maintained.

From a theoretical standpoint Wills ${ }^{11}$ has shown that, given the innermost and outermost radii of the system of three concentric hollow spheres or cylinders, the maximum shielding will be obtained when the inner and outer radii of the successive shells, and the air spaces separating them are in the same geometrical progression. Using transformer iron one could easily make up cylinders according to these specifications.

In practice it has been found desirable to use as much metal as possible and to place the iron shields as close as possible to the coils. In the earliest designs ${ }^{12}$ the writer, following the custom then in vogue, mounted the coils in a brass frame (having an excessive air space) surrounded with wrought-iron gas pipe $30 \mathrm{~cm}$ in length, $7,10, \mathrm{I} 5$, and $20 \mathrm{~cm}$ in diameter, and 4 to $6 \mathrm{~mm}$ in thickness. The smallest of these shields caused disturbances, due to permanent magnetization, and was discarded. The shielding was improved by adding a cylinder made of transformer iron (about $20 \mathrm{~cm}$ high and $9 \mathrm{~cm}$ in diameter; 8 turns; thickness $0.4 \mathrm{~mm}$ ) and a large outside shield $32 \mathrm{~cm}$ in diameter. This proved effective for a while, but, the magnetic disturbances in the vicinity of the laboratory becoming greater, the brass mounting-was discarded and the coils were embedded in Swedish iron. ${ }^{13}$ The fluctuation of the zero reading on the galvanometer scale is shown in Fig. 4 (dotted curve represents a second series of observations), when the coils were in a brass mounting (galvanometer No. I), the shields consisting of the "inner shield" of transformer iron (about I6 turns; thickness $0.4 \mathrm{~mm}$ ) and four cylinders of iron pipe, I2, I5, 20 , and $32 \mathrm{~cm}$, respectively, in diameter. In Fig. 5 is shown the fluctuation of the zero scale reading of galvanometer No. 2, consisting of the Swedish-iron mounting, the so-called inner shield of transformer iron ( $9 \mathrm{~cm}$ in diameter, $6 \mathrm{~mm}$ in thickness; about I 6 turns; thickness $0.4 \mathrm{~mm}$ ), and a cylinder of single thickness of soft iron pipe $20 \mathrm{~cm}$ in diameter. (See Table 2.) The observations on these two galvanometers, which stood side by side, were made in close succession, i. e., observations were made for three minutes, alternately, upon each galvanometer. They illustrate the much greater steadiness of the suspended needle system when in the ironclad (Swedish-iron) mounting. The next step was to 
add further shields to the ironclad mounting and cover the top with a layer of transformer iron about $5 \mathrm{~mm}$ in thickness. The complete shielding outfit of this galvanometer consisted of the Swedish-iron mounting, the "inner shield" of transformer iron, and the iron cylinders I2, I5, 20, and $32 \mathrm{~cm}$ in diameter. As

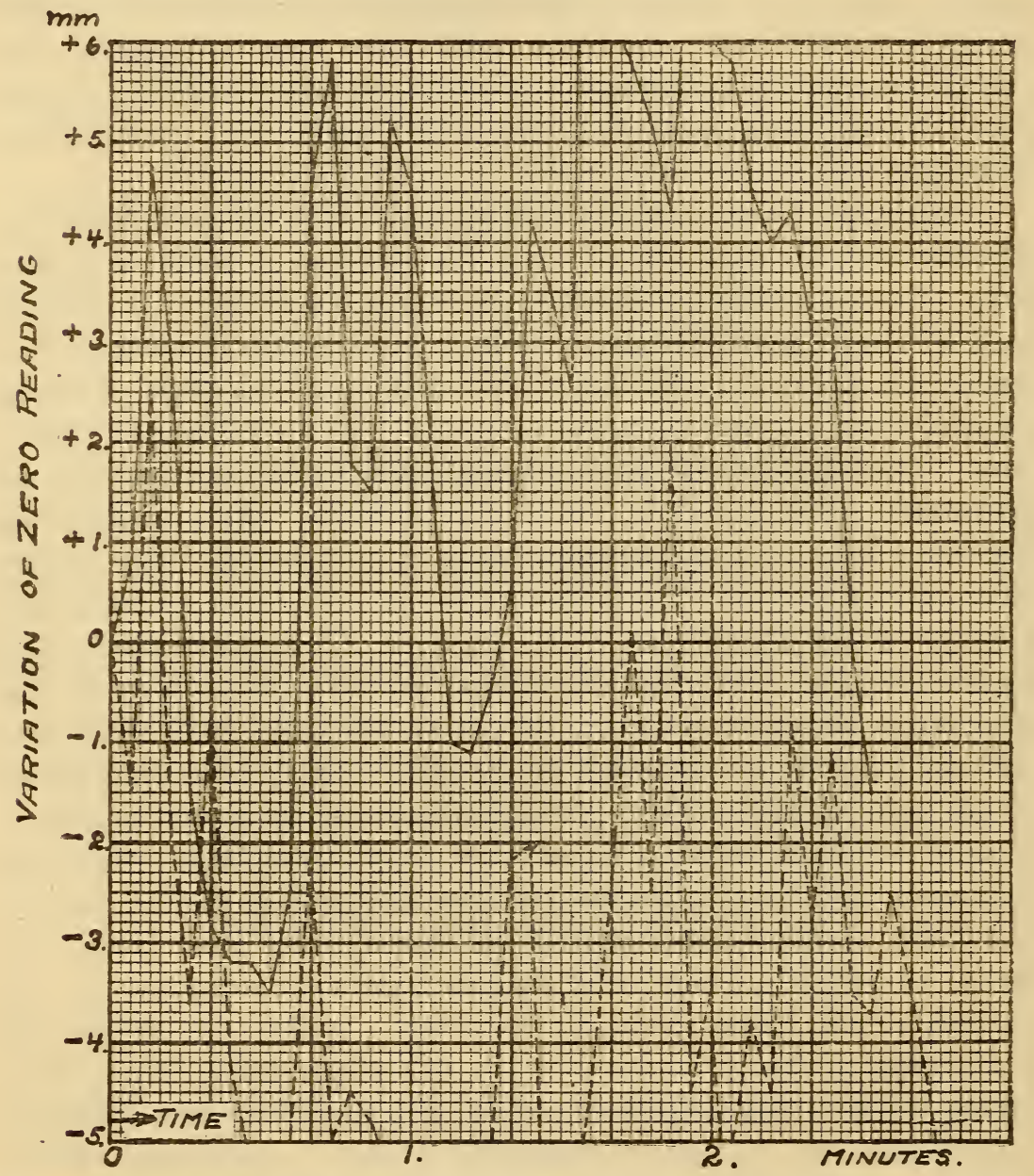

FIG. 4.-Flictuation of galvanometer needle when mounted in a brass frame and shielded with several cylinders of gas pipe

shown in Fig. 6, the fluctuations in the zero scale reading are reduced to $0.2 \mathrm{~mm}$, the galvanometer sensitivity being $i=5 \times 10^{-10}$ ampere and the complete period being less than three seconds. From this it may be seen that in view of the fact that only a few seconds of time are required to make a reading, one can easily obtain plenty of good observations without being obliged to make 


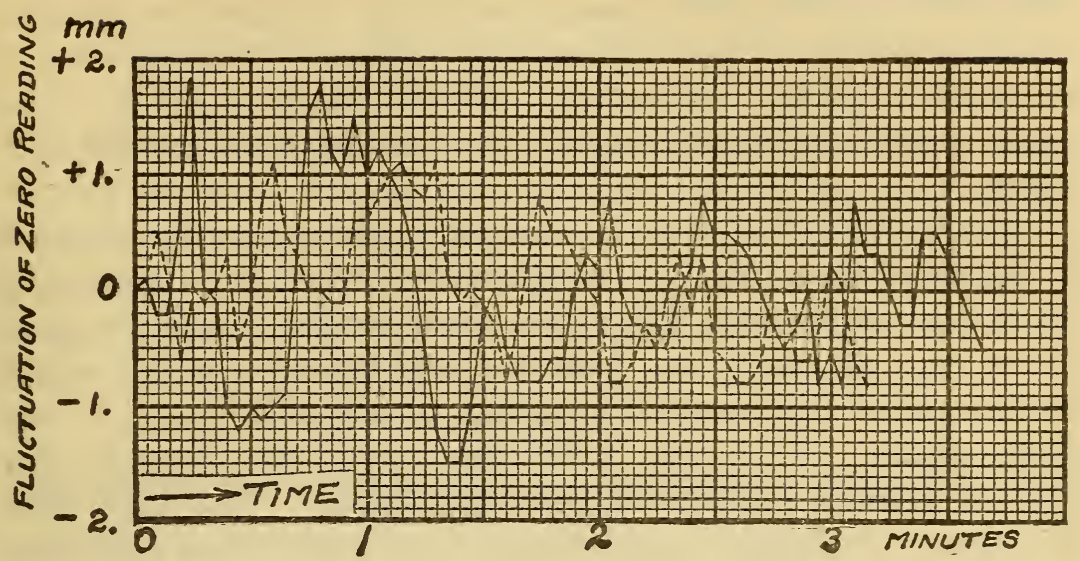

FIG. 5.-Fluctuation of zero reading of the needle in an ironclad mounting, surrounded with one cylinder of gas pipe $20 \mathrm{~cm}$ in diameter

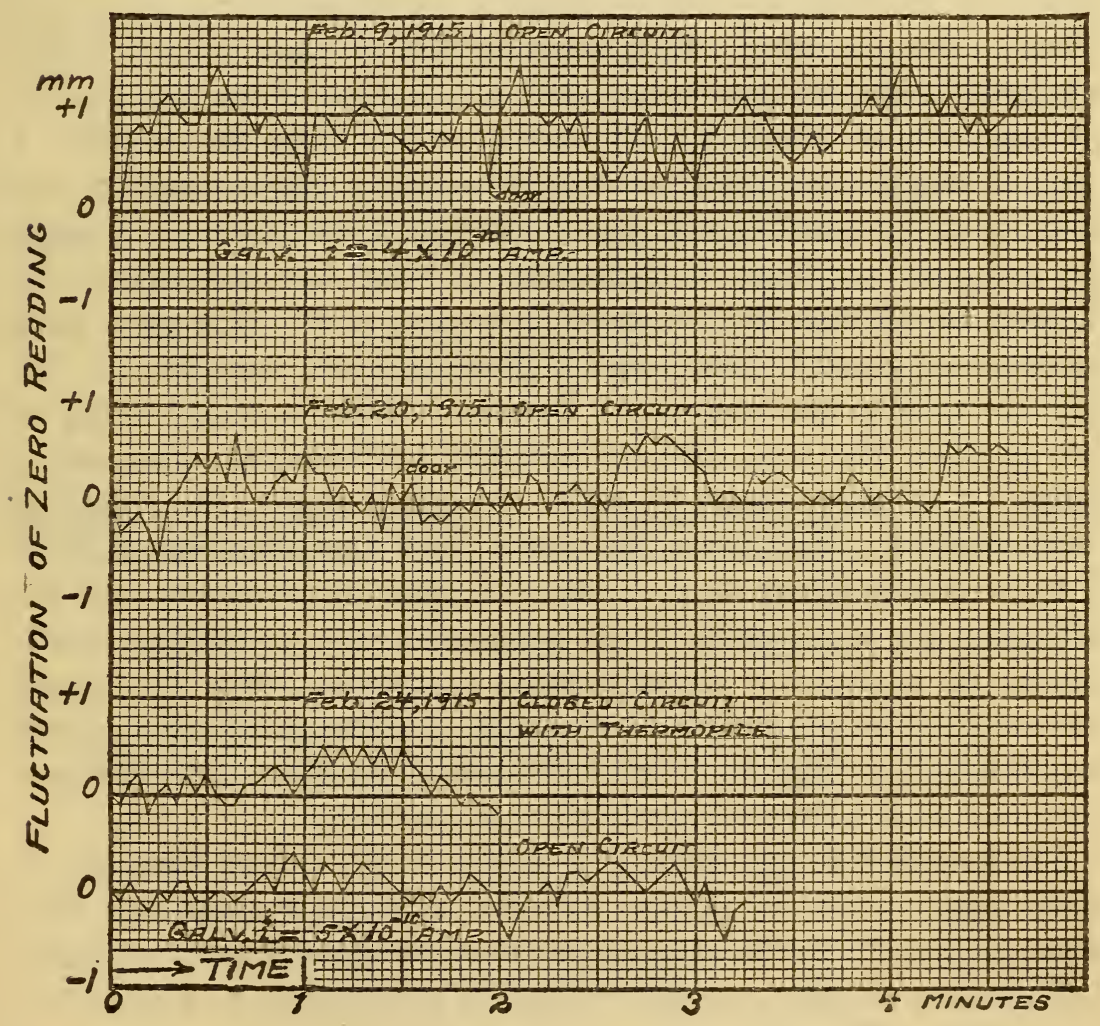

FIG. 6.-Fluctuation of the zero reading of ironclad galvanometer No. 2 when all the shields were in place 
measurements when the zero is unsteady. From the behavior illustrated in Fig. 6 it is evident that ordinary magnetic disturbances can be greatly reduced and that the Thomson galvanometer can be given a much wider application than has been possible heretofore.

The determination of the numerical value of the shielding was made on another ironclad galvanometer which is a duplicate of No. 2, just described. The test was made with a single magnet, $2 \mathrm{~mm}$ long, attached to a glass rod which held also the mirror. This magnet was suspended in a glass tube provided with a plane glass window. This glass tube rested upon the concrete base which supported the galvanometer and shields. The latter were, of course, temporarily removed and the magnet was suspended at the same height from the support as obtained when it was suspended in the ironclad (Swedish-iron) mounting. The deflecting field was produced by an electric current passed through a solenoid about $3 \mathrm{I} \mathrm{cm} \mathrm{long,} 5.5 \mathrm{~cm}$ in diameter, and containing about 280 turns of No. I 6 wire. This solenoid was at right angles to the magnetic meridian and was placed at the base of the galvanometer support, at a distance of about $42 \mathrm{~cm}$ from the needle. A control magnet was used to give the needle a single swing of two seconds under which conditions a current of 0.04 ampere through the solenoid produced a deflection of over $250 \mathrm{~mm}$ when the magnet needle was in the unshielded glass tube. The glass tube was then replaced by the ironclad (Swedish-iron) support, "I. C.," and the needle was suspended therein. Using a single swing of two seconds the 0.04 ampere through the solenoid produced a deflection of only about $25 \mathrm{~mm}$. In other words, the shielding ratio was ro. This is on the basis that the shielding ratio is $d_{1} t_{2} i_{2} \div d_{2} t_{1} i_{1}$ where $t_{1}, d_{1}, i_{1}$ are the time of vibration and the deflection for a current $i$, in the solenoid for the unshielded needle and $t_{2}, d_{2}, i_{2}$ are the corresponding quantities when the needle was shielded by the ironclad mounting. It was previously proven experimentally that for a given current, the deflection was proportional to the time of vibration of the needle.

The so-called inner shield ("I. S." in Table 2) was then put in place, when a current of 0.04 ampere (a larger current was used when all the shields were in place) through the solenoid produced a deflection of only $4.2 \mathrm{~mm}$, which is equivalent to a shielding ratio of 58 . This was verified the following day, giving the mean values assembled in Table 3 . The additional shields to this gal- 
vanometer consisted of five cylinders of extra heavy wroughtiron gas pipe, $25.5 \mathrm{~cm}$ in height and increasing in diameter from $12 \mathrm{~cm}$ for $S_{1}$ to $22 \mathrm{~cm}$ for $S_{5}$, as shown in Table 2. From the data given in Table 3 it is to be observed that the addition of one cylinder of wrought iron, $S_{1}$, produced a shielding ratio of 226 ; and that it required the complete set of five shields in order to produce a shielding ratio of about I 700 . Covering the top of these shields with three sheets of transformer iron increased the shielding ratio to about $\mathrm{i} 800$.

\section{TABLE 2}

Dimensions of Swedish Iron Mounting, I. C., and of Various Shields of Gas Pipe

lOutside dimensions of ironclad mounting, I. C., 4.8 by 5.0 by $9 \mathrm{~cm}$. I.ength of all shields, $25.5 \mathrm{~cm}$, except the inner shield, I. S., which was $16.5 \mathrm{~cm}$ in height.]

\begin{tabular}{|c|c|c|}
\hline Shield & $\begin{array}{l}\text { Inner } \\
\text { diameter }\end{array}$ & $\begin{array}{c}\text { Thichness } \\
\text { of wall }\end{array}$ \\
\hline Extra heavy: & $\mathrm{mm}$ & $\mathrm{mm}$ \\
\hline I. S..... & 78 & 7 \\
\hline $\mathrm{S}_{1} \ldots \ldots \ldots \ldots$ & 121 & 9.5 \\
\hline$S_{2} \ldots \ldots$. & 146 & 8.5 \\
\hline$S_{3} \ldots \ldots$. & 165 & 11.5 \\
\hline$S_{1} \ldots \ldots \ldots \ldots$. & 193 & 11.5 \\
\hline$S_{5} \ldots \ldots \ldots \ldots$ & 220 & 13.0 \\
\hline Single thickness: & & \\
\hline$s_{1} \ldots \ldots \ldots \ldots$ & 128 & 6 \\
\hline$S_{2} \ldots \ldots \ldots \ldots$ & 156 & 7 \\
\hline$S_{3} \ldots \ldots \ldots$. & 180 & 7.5 \\
\hline$S_{1} \ldots \ldots \ldots \ldots$ & 205 & 7 \\
\hline$S_{5}, \ldots \ldots \ldots \ldots$ & 228 & 8 \\
\hline
\end{tabular}

TABLE 3

Reduction in the Magnetic Disturbance of the Magnet Needle (the "Shielding Ratio") by Inclosing it in Various Cylinders of Extra Heavy Wrought Iron. (See Table 2)

\begin{tabular}{|c|c|}
\hline Kind of shield & $\begin{array}{l}\text { Shielding } \\
\text { ratio }\end{array}$ \\
\hline Ironclad mounting, I. C....... & 10.1 \\
\hline I. C. + I. S. ("inner shield") .......... & 57.5 \\
\hline I. C. + I. S. $+S_{1} \ldots \ldots \ldots \ldots \ldots \ldots \ldots$ & 226.0 \\
\hline I. C. + I. S. $+S_{1}+S_{2} \ldots \ldots \ldots \ldots \ldots \ldots$ & 373.0 \\
\hline I. C. + I. S. $+S_{1}+S_{2}+S_{3} \ldots \ldots \ldots \ldots \ldots$ & 675.0 \\
\hline I. C. + I. S. $+S_{1}+S_{2}+S_{3}+S_{1}+S_{5} \ldots \ldots$. & 1690.0 \\
\hline 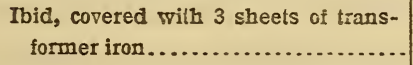 & 1790.0 \\
\hline $\begin{array}{l}\text { I. C. }+ \text { I. S. }+S_{1}+S_{2}+S_{3}+S_{4}+S_{5} \text { (all of } \\
\text { single thicimess) } \ldots \ldots \ldots \ldots \ldots \ldots\end{array}$ & 1040.0 \\
\hline Using an astatic system: & \\
\hline 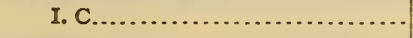 & 18.0 \\
\hline I. C. + I. S....................... & 71.0 \\
\hline
\end{tabular}


Using five cylinders of single thickness (see Table 2 for thickness of material) wrought-iron gas pipe, instead of the same number of extra heavy cylinders just described, the shielding ratio was only about one-half as large. This shows the importance of using the heaviest shields that can be obtained. The total weight of iron in this galvanometer when using the extra heary iron shields was orer $6+\mathrm{kgs}$.

The shielding-ratio is apparently only one-half that attained by Nichols and Williams. ${ }^{14}$ It is to be noted, homever, that they reduced their observations on the basis that the deflection produced is proportional to the square of the time of ribration. In the present test with all the shields in place, the time of vibration (single string) happened to be four seconds instead of two seconds which obtained when the magnet was in the unshielded glass tube. On the basis that the deflection is proportional to the square of the period (which is true only for a vacuum galvanometer) the shielding ratio would be four times the value recorded. From all the experimental data at hand, concerning the time of swing of a galvanometer needle in air, the reduction of observations on the basis of the square of the period is erroneous. In this test conditions were closely the same as those which obtain in practice, excepting that an astatic system is less easily perturbed than a single needle. From the experimental work of Nichols and Williams the shielding ratio would be greatly increased by annealing the iron cylinders. In the present test the cylinders were not annealed.

In view of the fact that this shielding test was not applied to galranometer No. 2 (Fig. 6) it may be added that its zero reading is as steady as the new galvanometer, showing that its shielding is sufficient in the present location, although it can not be as effective as the new combination which employs the extra mroughtiron cylinders just described.

\section{TEST OF A VACUUM GALVANOMETER}

In a previous paper ${ }^{15}$ experiments were described on the behavior of a certain galvanometer suspension in a vacuum of less than o.I mm. in which the sensitivity was not proportional to the square of the period, as was supposed to obtain when the air damping is removed. Evidently there was considerable damping by the residual air. It was therefore of interest to make a further test on a very light magnet system in a high vacuum produced by 
removing the residual air by means of hot metallic calcium. Furthermore, it was of interest to make the test on a single set of magnet needles instead of an astatic system, in view of the excellent magnetic shielding just described, which makes it possible to dispense with the astatic system of magnet needles. In the test just described on magnetic shielding, it was noticed that the single set of magnet needles was practically as well shielded as the astatic system consisting of two sets of magnet needles. The obvious advantages in using a single set of magnet needles are (I) the requirement of but two galvanometer coils and (2) the reduction of the weight of the magnet system; thus practically doubling the sensitivity. Theoretically, of course, each set of magnets in an astatic system is affected by the current in the adjacent coils. thus increasing the deflection. Hence, one set of magnet needles would not be so efficient magnetically in spite of the increase in sensitivity due to decrease in weight. In other words, the sensitivity would not be quite doubled by simply removing one set of magnets from the astatic system. Owing to mechanical difficulties in construction it is frequently found difficult to obtain agreement between theory and practice. However, in the present case there is a close agreement with theory. It will be shown presently that the single set of magnets, in an astatic pair, is not quite twice as efficient (sensitive) as the astatic pair.

In the experiments now to be described the sensitivity of an astatic system in air was determined for different periods. The lower set of magnets was then removed (see Fig. 2 for photographs of astatic magnet systems) and the sensitivity was again tested for different periods. In both tests only the two upper (2I-ohm) coils of the galvanometer previously employed in measuring heat from stars (Fig. 2) were used. The coils were joined in parallel giving a resistance of about Io ohms. A still higher sensitivity than was attained in the present tests is to be expected by using two coils of low resistance joined in series.

For making the test in a vacuum the galvanometer was placed on a ground glass and covered with a glass bell jar about $9 \mathrm{~cm}$ in diameter, which prevented the use of the "inner shield" of transformer iron. However, the other shields of soft wrought-iron gas pipe were sufficient to quite effectively shield the single set of magnets.

The vacuum was maintained by means of metallic calcium ${ }^{16}$ in a quartz-glass test tube, heated with an alcohol lamp. This was 
of course, merely a temporary arrangement for making this test. The vacuum galvanometer for star work will, of course, be properly designed as the results of these various tests.

The astatic system of magnets used in these tests consisted of two groups of magnets. Each group consisted of four magnets from $\mathrm{I} .4$ to $\mathrm{I} .6 \mathrm{~mm}$ in lenght, $0.25 \mathrm{~mm}$ in width, and $0.1 \mathrm{~mm}$ in thickness. The glass staff was O.I mm in thickness. The two groups of magnets were $29 \mathrm{~mm}$ apart; and the glass mirror was attached at the center of the staff. This glass mirror was platinized by cathode disintegration. It was made from especially prepared glass ${ }^{17}$ 0.1 $5 \mathrm{~mm}$ in thickness. Its surface was $1.3 \mathrm{~mm}$ by $1.6 \mathrm{~mm}$. By using a telescope with a very good eyepiece, a still smaller mirror could be used. In photographic registration a much smaller mirror could be used, thus increasing the sensitivity.

The current used to excite the galvanometer was $i=1.45 \times 10^{-8}$ amperes. This produced the deflections shown in curve I, Fig. 7 , the scale being at $1.4 \mathrm{~m}$. Using this suspension the deflection is directly proportional to the period, as reported in previous papers, when using heavy suspensions in air.

On removing the lower set of magnets, the weight of the suspension (which was now about $1.8 \mathrm{mg}$ ) was so much reduced that slight tremors were noticeable. As shown in curve 2, Fig. 7, the sensitivity was about doubled by removing the lower set of magnets. This curve gives observations made on two different days, the values being slightly lower on the second day. The air damping is very marked as shown by the curvature in the graph.

On reducing the air pressure to about 0 . I $\mathrm{mm}$ the sensitivity of this set of magnets, for a two-second swing is 2.5 times that of the astatic system. Finally, by removing the residual air by heating the metallic calcium, the sensitivity is proportional to the square of the period (curve 3, Fig. 7), so that by changing the time of single swing from two seconds to six seconds the sensitivity is increased from $i=9 \times \mathrm{IO}^{-11}$ amperes to $i=\mathrm{I} \times \mathrm{IO}^{-11}$ amperes. The previous work on stars indicated that a single swing of five to six seconds is easily controlled.

With all the air removed a new difficulty arises from the lack of damping of the galvanometer needle, which keeps swinging back and forth ro to 5 times before coming to rest. In practice it may therefore be better to have a small amount of air present for 
damping, instead of providing other means for bringing the needle to rest.

The performance of the galvanometer suspension used in I9I4 in measuring the radiation from stars ${ }^{18}$ is shown in curve 5 , Fig. 7 ,

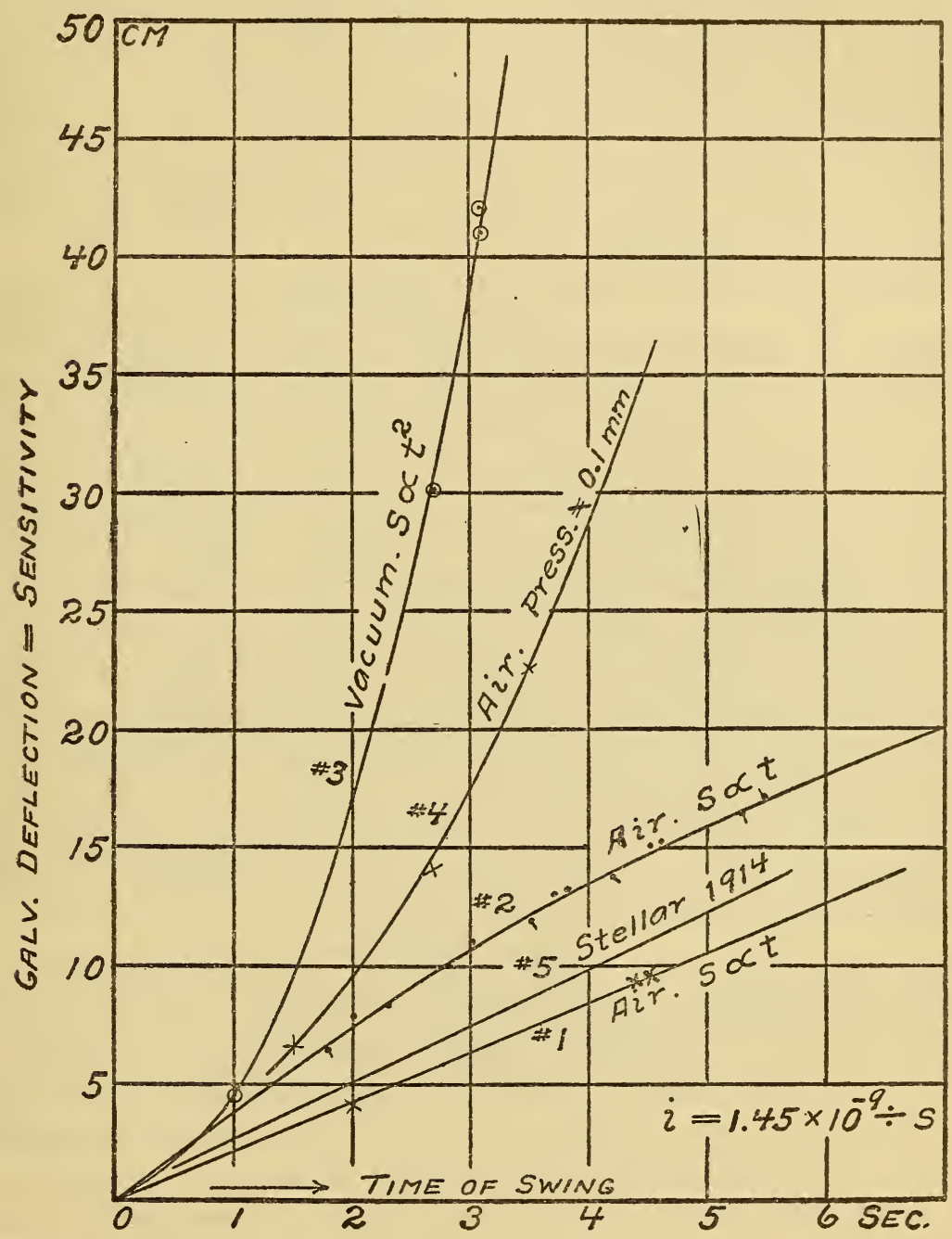

FIG. 7.-Test of current sensitivity of a galvanometer in air and in a vacuum the time of single swing being about three seconds and the sensitivity being about $i=2 \times 1 \mathrm{IO}^{-10}$ amperes for a scale at $2 \mathrm{~m}$. The sensitivity of that suspension in air is therefore somewhat (20 per cent) higher than the one used in the present test. Hence, using 
only one set of magnets of this astatic pair, a still higher sensitivity is to be expected than was attained with the suspended system just described.

From the foregoing tests it is evident that the sensitivity of this outfit is about Io times (for the same swing) that used in the preceding measurements of heat from stars. This was accomplished by using a lighter suspension in a vacuum. It is to be remembered, however, that a lighter suspension had been provided for the previous work, but not having a separate pier for the galvanometer no attempt was made to use a higher sensitivity than $i=\mathrm{I} \times \mathrm{IO}^{-10}$ amperes.

These tests are, of course, only preliminary and of a cursory nature. By concentrating one's efforts upon the vacuum galvanometer as it will be used (by trying various suspensions) it appears possible to produce a sensitivity of $i=5 \times 10^{-12}$ amperes on a single swing of five to six seconds, so that by reading to a fractional part of a scale division one can observe deflections caused by currents of the order of $I \times I^{-12}$ amperes. Such a high sensitivity is possible with the set of magnets used in the present test by lengthening the time of swing from eight to nine seconds. The general experience in radiometric work is that, at certain times, meteorological conditions are sufficiently steady so that the time of single swing of the galvanometer can be increased to I2 or I 5 seconds (observations on curve 2, Fig. 7, were made on a single swing of $\mathrm{I} 6$ to $\mathrm{I} 7$ seconds), thereby enabling one to obtain a sensitivity of $i=\mathrm{I} \times \mathrm{IO}^{-12}$ amperes, and, by reading fractional parts of a scale division, $5 \times 1 \mathrm{I}^{-13}$ amperes.

For controlling such a high sensitivity it will be necessary to design the instrument so as to shield it from static changes such as were observed in the previous measurements of stellar radiation,

In the previous paper, ${ }^{19}$ giving the measurements on the radiation from stars, the conclusion arrived at was that it is desirable to increase the sensitivity of the stellar radiometer 20 times; by increasing the sensitivity of the thermopile 2 times and the galvanometer Io times. The foregoing experiments indicate the manner in which the galvanometer sensitivity may be easily increased by Io to $I_{5}$ times that used in the previous investigation. 


\section{SUMMARY}

The present paper gives the results of an investigation of the force exerted by various galvanometer coils as compared with a set of three coils used as standards. Some of the coils were wound according to theoretical requirements, while others were wound empirically. Numerical data are given relating to the force exerted by coils having various resistances. A simple coil is described, wound with a single size of wire (No. 28) which was found to be very efficient.

A 9-ohm coil (see test on the 8.6-ohm coil) is described which is very efficient and is well adapted to be used with the bismuthsilver thermopiles previously described.

A comparison is made of various astatic magnet systems and data are given showing the importance of using small mirrors in order to increase the sensitivity.

Experiments are described on shielding the galvanometer needle from external magnetic disturbances. The galvanometer coils are mounted in cavities cut into blocks of Swedish iron, which reduce the air space and act as a magnetic shield. This elimination of convection currents greatly improves the steadiness of the needle system. Various shields are described, consisting of laminated cylinders made from transformer iron and solid cylindrical shells cut from wrought-iron gas pipe. By imbedding the galvanometer coils in blocks of Swedish iron which are surrounded by cylindrical shells of transformer iron and of wrought iron, the effect of external magnetic perturbations upon the astatic needle system is easily reduced to $\mathrm{I} / 2000$ of its original value.

Experiments on a vacuum galvanometer are described, in which a sensitivity was attained which is more than tenfold that used in the writer's previous work on stellar radiation.

WASHINGTON, October 8, I9I 5 . 


\section{APPENDIX}

\section{NOTE I. MOUNTING FOR VACUUM THERMOPILES}

The object of this note is to summarize some of the results given in previous papers on thermopiles and to describe a new mounting for vacuum thermopiles.

During the past few years there has arisen a need for a sensitive radiometer for measuring light stimuli which are used in various physical, physiological, and psychological problems. The instrument must be simple in operation so that it can be used by experimenters who have had but little experience in radiometry. The linear thermopile of bismuth ${ }^{20}$ with connecting wires of copper or silver was designed with the riew of supplying this need of a sensitive radiometer which can be operated in air, thus avoiding an additional equipment for maintaining a vacuum. Hotrever, as mentioned in previous papers, the linear thermopile is not an efficient instrument in comparison with a single thermojunction. For example, a linear thermopile of I 6 junctions is only four times as sensitive as a single junction of this same instrument. In a vacuum, such as one can easily produce with an oil pump, the sensitivity of the linear thermopile is doubled, so that, by reducing the gas pressure to 0.005 to $0.01 \mathrm{~mm}$, the sensitivity of the linear thermopile is from eight to ten times that of a single junction of bismuth-silver (or copper) in air.

Copper or silver connecting wires are used in the linear thermopile in order to maintain a low resistance. When using a single thermocouple the resistance is of minor importance. It is therefore possible to increase the radiation sensitivity of the thermojunction by using a metal which has a lower heat conductivity than copper or silver. In the thermocouples used in measuring heat from stars ${ }^{21}$ the radiation sensitivity was doubled by connecting the bismuth with platinum instead of silver wire. The radiation sensitivity of the bismuth-platinum thermocouple was further increased four to five times when it was used in a vacuum maintained by means of metallic calcium, so that the total radiation sensitivity was about ten times that of a single bismuth-silver 
thermojunction used in air. In other words, this single junction of bismuth-platinum, in a high vacuum, was about twice as sensitive as a linear thermopile in air, having 16 junctions of bismuthcopper (or silver) and having sixteen times the receiving surface. However, greater care is required in operating the vacuum thermocouple.

The method of construction of a radiometer depends entirely upon the manner in which the instrument is to be applied. The most common use of a thermopile is no doubt in connection with spectral energy measurements, and the present discussion has reference to this particular application. As mentioned in previous papers, but little work has been done on the radiation from solids and gases in the visible and ultra-violet part of the spectrum. This is attributable chiefly (I) to the low intrinsic brilliancy of most of the present-day illuminants, (2) to the low lightgathering power of the telescopes used in the spectrometers, and (3) to the low sensitivity of the radiometers. The amount of energy to be measured is defined by the width and height of the spectrum. By using a curved radiometer slit which fits the curvature of the image of the spectroscope slit it is possible to utilize a greater height of the spectrum than is possible with the slits which are usually supplied by makers of spectroscopic apparatus, and the amount of radiant energy available is proportionately increased. In cases where the absorption of the mirror is negligible or where corrections can be applied to the energy measurements it is more efficient to use a single thermojunction and concentrate the whole spectral line upon it by means of a concave cylindrical mirror than to use a linear thermopile which intercepts the whole length of the spectrometer slit. ${ }^{22}$ By this means one will obtain about sixteen times the sensitivity of a single thermojunction, whereas a sensitivity (a galvanomer deflection) of only four times that of a single junction would be produced by a linear thermopile of 16 junctions which intercepted all the radiations falling upon the spectrometer slit.

The thermopile, while more steady than a bolometer, is not entirely free from disturbances by air currents. It is therefore desirable to use it in a well-constructed chamber which can be evacuated. This increases both the steadiness of the galvanometer readings and the sensitivity of the radiometer. It is desirable to be able to use the instrument in an independent mounting as 
well as when attached to a spectroscope. Both the vacuum arrangement and the interchangeable mounting are therefore embodied in a new design shown in Fig. 8, which shows the container for the thermopile raised, thus exposing the spectrometer slit, $S$. The vacuum container is provided with a wide (I $2 \mathrm{~mm}$ ) flange and the cover is sufficiently thick $(5 \mathrm{~mm})$ to prevent warping, so that the vacuum is more easily maintained than in the design previously described. The opening for admitting radiation upon the thermopile is covered with a window, as shown in Fig. 4 of the previous paper. ${ }^{23}$ The lead wires of the thermopile are brought out of the container by passing them through a fiber bushing and attached to copper binding posts, as shown in the photograph. A bit of Chatterton compound is applied at the point where the wires emerge from the fiber bushing. In this manner it is possible to easily produce an air-tight connection to the thermopile.

In the designs previously described, the heavy copper binding posts, which acted as heat reservoirs, extended into the containing vessel, and the lead wires to the thermopile were attached on the inside of the receptacle. In this manner air currents could not easily cause temperature fluctuations in the wires. In the present design the conducting wires to the thermopile are attached, within the receptacle, to heavy (No. 24) copper wires which pass through the insulating bushing to the heavy copper binding posts, as shown in Fig. 8. Air currents across the exposed parts of these wires may cause temperature fluctuations which may be communicated to the thermopile. The exposed parts of these heavy lead wires between the binding posts and the container are therefore covered with rubber tubing in order to shield them from air currents. The lead wires to the galvanometer are heavy "twisted lamp cord," as previously described. 
Bulletin Bureau of Standards, Vol. 13

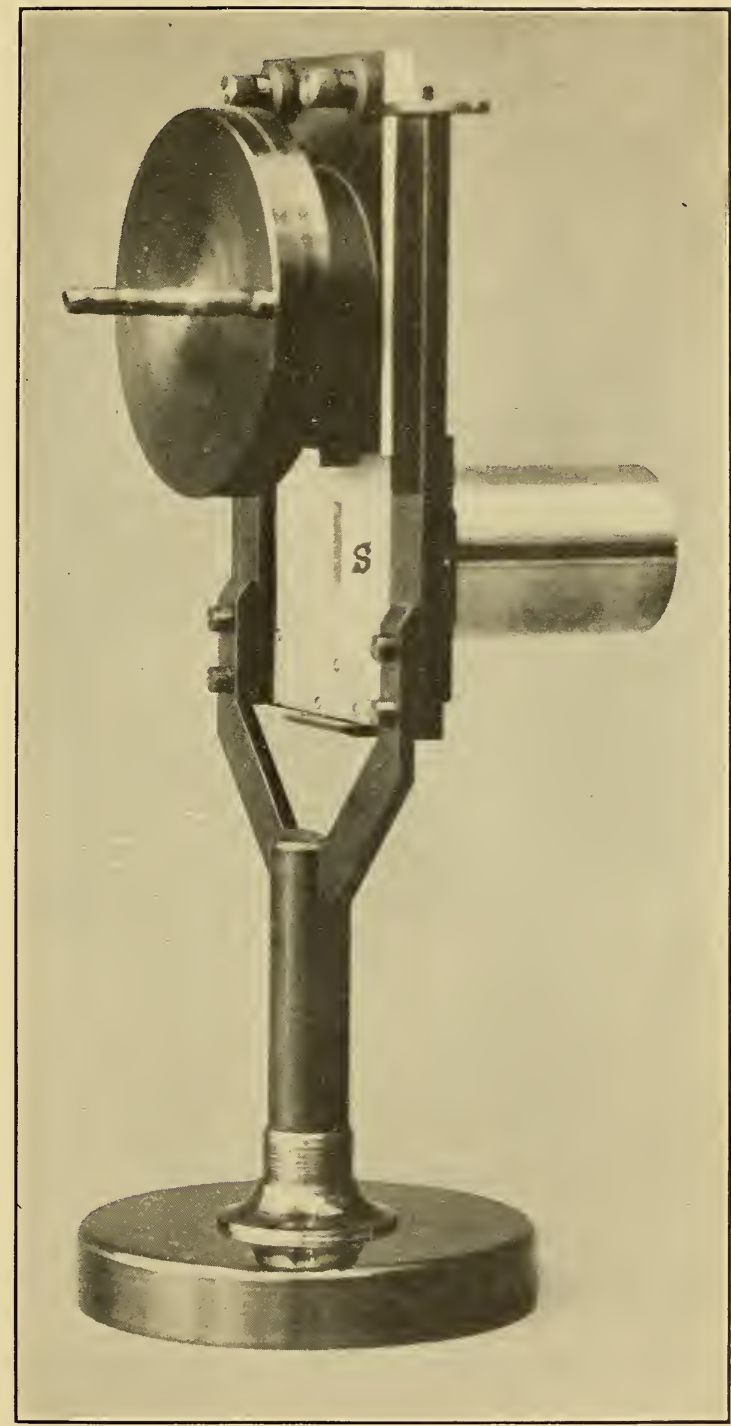

FIG. 8.-Mounting for a vacuum thermopile which can be attached to a spectrometer 